\title{
Incorporating the Lessons Learned from the 2012 East Azerbaijan Earthquakes in Iran's National Health Emergency Plan
}

\author{
Ali Ardalan, MD, PhD; ; Javad Babaie, MSc; ${ }^{1,2}$ Mohamad Javad Moradian, MD, MPH; ${ }^{1,2}$ \\ Mohamad Shariati, MD; ${ }^{3}$ Homa Yousefi, MSc, $\mathrm{MPH}^{4}$
}

1. Department of Disaster Public Health, School of Public Health, Tehran University of Medical Sciences, Tehran, Iran

2. Department of Disaster \& Emergency Health, National Institute of Health Research, Tehran University of Medical Sciences, Tehran, Iran

3. Department of Health Network Management, Ministry of Health and Medical Education, Tehran, Iran

4. Disaster Management and Risk Reduction Unit, Ministry of Health and Medical Education, Tehran, Iran

\section{Correspondence:}

Ali Ardalan, MD, PhD

78, Italia Ave, $2^{\text {nd }}$ Floor

National Institute of Health Research

Tehran University of Medical Sciences

Tehran, Iran

E-mail: aardalan@tums.ac.ir

\author{
Abbreviations: \\ DPHC: District Public Health Center \\ PHEOP: Public Health Emergency Operation \\ Plan \\ Online publication: April 8, 2013
}

doi:10.1017/S1049023X13000319
Revisions to Iran's National Public Health Emergency Operation Plan (PHEOP) are currently underway. ${ }^{1}$ Lessons learned from the recent twin earthquakes in East Azerbaijan in northeast Iran can be incorporated to enhance the health sector response.

On August 11, 2012, two consecutive magnitude 6+ earthquakes hit East Azerbaijan (EA) province in Iran at 4:53 PM and 5:04 PM local time. The quakes led to 303 deaths and 2,600 injuries, and affected 60,000 people across 182 villages.

The Ministry of Health and Medical Education deployed an assessment team to Tabriz (the capital of province) along with a team of technical advisers. Massive medical and search and rescue operations were undertaken during the first 24 hours, and were followed by public health operations. ${ }^{2}$ Here, we would like to address two main challenges that have bearing on revisions to the PHEOP.

The health system in three affected districts of East Azerbaijan province was severely damaged. According to the existing emergency plan, the District Public Health Centers (DPHCs) are focal points for management of disaster response. In this event, all three DPHCs in addition to 89 health houses were damaged, and failed in their functions. ${ }^{2} \mathrm{As}$ a result, mutual assistance was invoked from neighboring districts. While health workers were able to take on some of the functions of the damaged centers, they could not effectively take on the coordinating role for disaster response. To prevent this problem in the future, we propose the development of Disaster Public Health Assistance Teams (DPHATs) to be incorporated into Iran's new emergency plan. Disaster Public Health Assistance Teams must be equipped for two functions: (1) to support the DPHC in terms of command and coordination functions; and (2) to augment the provision of health services in damaged centers for the first 72 hours.

A second lesson learned in this disaster was the lack of real-time integration and georeferencing of data collected. This limitation of the health information management system (HIMS) caused delays in assessment and response to this disaster. In addition, it was difficult to adapt instruments to evolving data needs. The current disaster plan underestimated the ability to re-establish telecommunications service in the wake of an earthquake. In fact, we found that coverage was provided quickly to most areas, within 24-72 hours after the event. We propose that the new plan should emphasize the use of crowd-sourced, geo-referenced data using GSM (Global System for Mobile Communications) messaging from a trusted network of health staff.

\footnotetext{
References

1. Ardalan A, Moradian MJ, Goya M, et al. National Public Health Emergency Operations Plan. Tehran: Ministry of Health and Medical Education; 2012.

2. Disaster Management and Risk Reduction Unit. Report of Public Health Operations in August 11, 2012 East Azerbaijan Earthquake. Tehran: Iran's Ministry of Health and Medical Education; September 2012.
} 